\title{
OPTIMUM ANCHORING FOR LONG SPAN CABLE-STAYED BRIDGES
}

\author{
By Hisanori OHTSUKA*, Toshiaki OHTA** and Fujio IMAI***
}

\begin{abstract}
This paper presents the formulas to compare the cost of cable-stayed and suspension bridges. Three types of cable-stayed bridges with full, self and partial anchorages and two types of suspension bridges with full and self anchorages are considered. With the cable-stayed bridges, fan, harp and semi-harp types are treated. The structural components counted in cost comparisons are superstructures (cables, hanger ropes and steel in main girders), towers and anchorages.

The numerical calculations are conducted varying the number of hangers and stays, span sag ratio, the locations of expansion joints in partially anchored cable-stayed bridges and the cost of anchorages. The numerical results in this paper show that partially anchored fan type bridges are the most suitable for long spans.
\end{abstract}

\section{INTRODUCTION}

Suspension bridges are usually classified into self anchored and fully anchored types. In the former, cables are directly anchored to the main girders. In such case, no enormous anchorage is required due to its self-balanced mechanism, but this type is unfavorable in terms of the erection procedures and the saving of materials.

With cable-stayed bridges, the self anchored type has been generally constructed until now. The same unfavorable reasons prevent this type from spreading its span length in such ranges as the long suspension bridges do.

In 1966 Gimsing, N.J.' investigated the possibilities and advantages of using an earth-anchored system (either a fully anchored or a partially anchored system) for cable-stayed bridges. He clarified that by anchoring the cables, an increased stiffness of the cable system is obtained and that anchored stayed bridges is a competitive solution for bridges with main spans ranging from approximately $300 \mathrm{~m}$ to $800 \mathrm{~m}$. Furthermore he ${ }^{2)}$ made it clear that a fan shaped cable system will significantly reduce the amount of cable steel compared to the suspension system and that the earth anchoring of the back stay in a fan shaped cable system can reduce the normal forces acting on the main girders.

Gilsanz, R.E. et $\mathrm{a}^{3}$, extended the idea presented by Gimsing. They developed the formulas to compare the cost of the super-structure for cable-stayed and suspension bridges. Comparing the structural efficiency of the different kinds of bridges, they concluded that partially anchored fan type cable-stayed bridges are the most efficient for spans up to $1846 \mathrm{~m}(6000 \mathrm{ft})$.

* Member of JSCE Dr. Eng., Assoc. Professor, Department of Civil Eng., Kyushu Univ. (Hakozaki, Higashi-ku, Fukuoka, 812)

** Member of JSCE Dr. Eng., Professor, Department of Civil Eng., Kyushu Univ. (Hakozaki, Higashi-ku, Fukuoka, 812)

*** Member of JSCE Research Associate, Department of Civil Eng., Kyushu Univ. (Hakozaki, Higashi-ku, Fukuoka, 812) 
This paper investigates the optimum anchoring for long span cable-stayed bridges by comparing costs of partially and fully anchored cable-stayed bridges to those of self anchored cable-stayed bridges and fully and self anchored suspension bridges.

This paper introduces more general formulas to calculate the cost by making improvements on afterward mentioned points. Using these equations, more practical results for the optimum anchoring of long span cable-stayed bridges may be obtained.

\section{MODELING}

The same modeling procedure as used by Gilsanz, R.E. et $\mathrm{al}^{33}$ is utilized in this analysis, i.e. the bridges are considered to consist of roadway, superstructure, towers and anchorages. In this paper, to simplify formulas, the cost of the roadway is considered to be the same for all types of bridges as considered by Ref. 3). It is pointed out in Ref. 3) that this way of modeling clearly favors the suspension bridges.

The features of this paper are as follows.

1) Each cable is considered to have uniform section.

2) In partially anchored cable-stayed bridges, the cost formulas are introduced considering that the expansion joints are located in arbitrary points of the main girders in side spans. Therefore fully and self anchored cable-stayed bridges are treated as one particular case of partially anchored bridges. This also enables the cost comparison with the partially anchored bridges which have expansion joints in different locations.

3) According to the demand for anchoring the cable to the towers and main girders in multi-cablestayed bridges, semi-harp type cable-stayed bridges become a practical type of structtures. In this study the cost formulas for semi-harp type bridges are originally introduced, and the cost comparison is conducted between semi-harp, harp and fan types.

4) Practical span sag ratios for cable-stayed bridges are different from that for suspension bridges, and the statical efficiency of the cables varies with the change in the height of the towers. Therefore in this study span sag ratio is treated as variable.

5) The cost of towers and anchorages are originally considered.

\section{FORMULAS FOR COST EVALUATION}

\section{(1) Superstructure of Suspension Bridges}

In the reference 3 ), the weight of the main cable is obtained assuming a variable cross section. Since the main cable has practically uniform section, the weight of the main cable $\left(w_{m c}^{\prime}\right)$ is obtained by Eq. ( 1$)$ in this paper.

$$
w_{m c}^{\prime}=\sum_{j=1}^{j=N / 2} \frac{F_{c H} l_{j}}{\sigma_{c} \cos \alpha_{1}} \gamma
$$

in which $\sigma_{c}=$ allowable stress in the cable, $\gamma=$ specific weight, $F_{C H}=$ horizontal component of cable tension, $l_{j}=$ length of the cable between $j$ and $j-1, \alpha_{1}=$ angle between the cable at point $j=1$ and the horizontal, and $N=$ number of hangers in the center span.

From Eq. (1) we obtain the following Eq. (2).

$$
w_{m c}^{\prime}=\frac{\gamma}{\sigma_{c}} \sqrt{1+\left\{\frac{4 H(N+1)}{L(N+2)}\right\}^{2}}\left(\frac{P L^{2}}{8 H} \frac{N+2}{N+1}\right) \sum_{j=1}^{j=N / 2} \sqrt{\left(\frac{L}{N+1}\right)^{2}+\left\{\frac{4 H(N+2-2 j)}{N(N+2)}\right\}^{2}} .
$$

in which $H=$ sag of the cable equal to the tower height ; $L=$ length of the main span; and $P=$ distributed load $(\bar{P} N=P L)$. The weight of the cable that lies horizontally at the center of the span $\left(w_{c H}\right)$ is obtained by Eq. (3) considering that the cable has uniform sectional area.

$$
\begin{aligned}
w_{C H} & =F_{C H} l_{H} \gamma / 2 \sigma_{c} \cos \alpha_{1} \\
& =\frac{P L^{2}(N+2) \gamma}{16 \sigma_{c} H(N+1)} \sqrt{\left(\frac{L}{N+1}\right)^{2}+\left(\frac{4 H}{N+2}\right)^{2}}
\end{aligned}
$$


The weight of hangers $\left(w_{h a}\right)$ is given as follows ${ }^{3)}$ :

$$
w_{h a}=\sum_{j=1}^{j=N / 2} \gamma \frac{\bar{P}}{\sigma_{c}}\left(H-y_{j}\right)=\frac{\gamma P L H}{\sigma_{c}} \frac{N-2}{6 N}
$$

The total cable weight is:

$$
\begin{aligned}
& w_{c t}=2\left(L+2 L_{1}\right) / L\left(w_{m c}^{\prime}+w_{c H}+w_{h a}\right) \\
& =\frac{P\left(L+2 L_{1}\right) \gamma}{\sigma_{c} H}\left[\frac{L}{4} \frac{N+2}{N+1} \sqrt{1+\left\{\frac{4 H(N+1)}{L(N+2)}\right\}^{2}} \sum_{j=1}^{j=N / 2} \sqrt{\left(\frac{L}{N+1}\right)^{2}+\left\{\frac{4 H(N+2-2 j)}{N(N+2)}\right\}^{2}}\right. \\
& \left.+\frac{L}{8} \frac{N+2}{N+1} \sqrt{\left(\frac{L}{N+1}\right)^{2}+\left(\frac{4 H}{N+2}\right)^{2}}+\frac{H^{2}(N-2)}{3 N}\right]
\end{aligned}
$$

in which $L_{1}=$ length of side span.

The weight of steel in the horizontal for a self anchored suspension bridge is given as follows ${ }^{3)}$ :

$$
w_{\mathrm{sssa}}=\frac{F_{C H}}{\sigma_{\mathrm{sco}}}\left(L+2 L_{1}\right) \gamma=\frac{\gamma P L^{3}(N+2)}{8 H \sigma_{\mathrm{sco}}(N+1)}(1+2 R)
$$

in which $\sigma_{\text {sco }}=$ allowable stress in compression and $R=L_{1} / L$.

(2) Superstructure of Cable-Stayed Bridges

a) Cable Weight

Assume that the amount of cable steel for the side spans is equal to the amount of steel for the main span and that the stays are equally spaced all along the bridge (Fig. 1). The total cable weight of fan type $\left(w_{c j}\right)$,
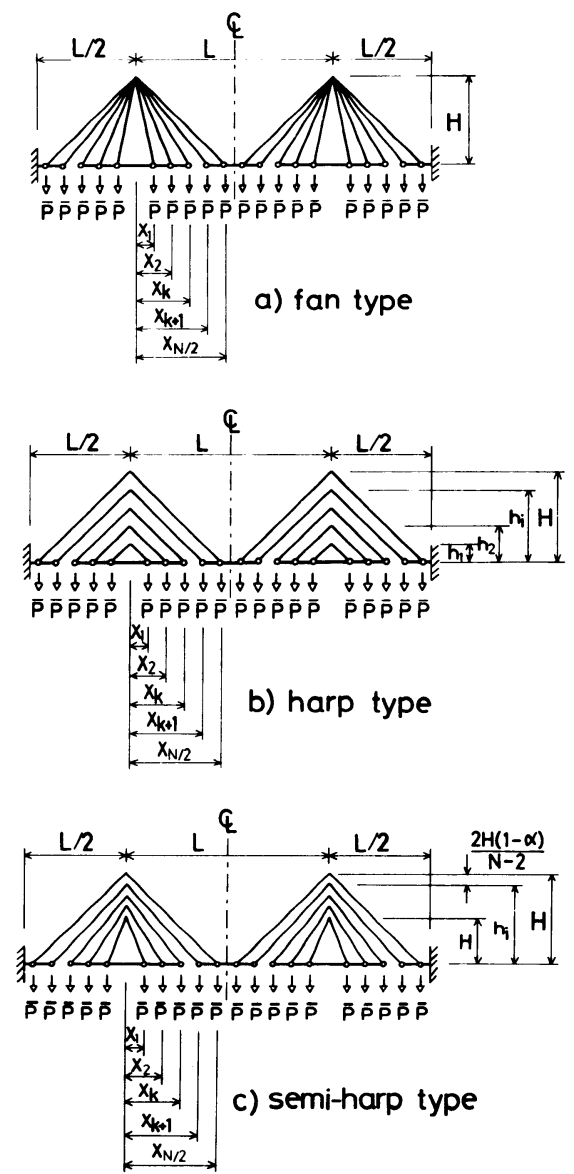

Fig. 1 Superstructure of Partially Anchored Cable-Stayed Bridges. harp type $\left(w_{c h}\right)$ and semi-harp type $\left(w_{c s h}\right)$ is given by Eqs.

(7), (8) and (9) respectively.

$$
\begin{aligned}
& w_{c f}=4 \sum_{i=1}^{i=N / 2} F_{c i} l_{c i} \frac{\gamma}{\sigma_{c}}=\frac{\gamma P L^{2}}{\sigma_{c}}\left[S S R \frac{N+2}{6(N+1)}+\frac{2}{S S R}\right] \\
& w_{c h}=\frac{\gamma P L^{2}}{\sigma_{c}}\left[S S R \frac{N(N+2)}{4(N+1)^{2}}+\frac{1}{S S R} \frac{N+2}{N}\right] \\
& w_{c s h}=\frac{\gamma P L^{2}}{\sigma_{c}}\left[\frac { 4 } { L N } \sum _ { i = 1 } ^ { i = N | ^ { 2 } } \left\{\frac{(L /(N+1))^{2} i^{2}}{\alpha H+2 H(1-\alpha)(i-1) /(N-2)}\right.\right. \\
& \left.\left.+\alpha H+\frac{2 H(1-\alpha)(i-1)}{(N-2)}\right\}\right]
\end{aligned}
$$

in which $S S R=L / H$ (span sag ratio), $\alpha=$ ratio of lowest cable height to tower height. Eqs. (7) and (8) are the same as given in Ref. 3).

b) Weight of Main Girders

The amount of main girders of the side spans is assumed to be equal to the main girders of the center span. The weight of the main girders for the partially anchored case is given as follows.

$$
\begin{aligned}
& w_{s f p a}=4 \sum_{i=1}^{i=k} \frac{F_{s i} x_{i}}{\sigma_{s c o}} \gamma+4 \sum_{i=k+1}^{i=N / 2} \frac{F_{s i} \gamma}{\sigma_{s t e}}\left(\frac{L}{2}-x_{i}\right) \\
& =\frac{\gamma P L^{2}}{\sigma_{\text {ses }}}[S S R] \quad \text { (Fan type) } \\
& w_{s h p a}=\frac{\gamma P L^{2}}{\sigma_{s e h}}[S S R] \quad(\text { Harp type }) \\
& w_{s s h p a}=\frac{\gamma P L^{2}}{\sigma_{s e s h}}\left[\frac{4 L}{N(N+1)^{2}}\right] \quad \text { (Semi-harp type) }
\end{aligned}
$$

in which 


$$
\begin{aligned}
& \sigma_{\text {sef }}=12 N(N+1)^{2} /\left[8 k(k+1)(2 k+1) / \sigma_{\text {sco }}+\{N(N+1)(N+2)-4 k(k+1)(3 N-4 k+1)\} / \sigma_{\text {ste }}\right] \\
& \sigma_{\text {seh }}=(N+1)^{2} /\left[k(k+1) / \sigma_{\text {sco }}+(N-2 k)^{2} / \sigma_{\text {ste }}\right] \\
& \sigma_{\text {sesh }}=1 /\left[\frac{1}{\sigma_{\text {sco }}} \sum_{i=1}^{i=k} \frac{i^{2}}{\alpha H+2 H(1-\alpha)(i-1) /(N-2)}+\frac{N+1}{\sigma_{\text {ste }}} \sum_{i=k+1}^{i=N / 2} \frac{i / 2-i /(N+1)}{\alpha H+2 H(1-\alpha)(i-1) /(N-2)}\right]
\end{aligned}
$$

in which $\sigma_{s t e}=$ allowable stress in tension.

Expansion joints are inserted in the main girders between cables $k$ and $k+1$. Therefore $k=0$ for fully anchored types, $k=N / 2$ for self anchored types and $0<k<N / 2$ for partially anchored types. Calculating $\sigma_{\text {sesh }}$ in Eq. (12) only the second term of the denominator is used for fully anchored types $(k=0)$, and only the first term of the denominator is used for self anchored types $(k=N / 2)$. Using Eqs. (10), (11) and (12), all types of cable-stayed bridges are treated systematically.

\section{(3) Cost of Superstructure}

The formulas derived are of the following type :

$w_{c}=\gamma P L^{2} B_{c} / \sigma_{c}, w_{s}=\gamma P L^{2} B_{s} / \sigma_{s}$

in which $B_{c}$ and $B_{s}$ are coefficients defined in square bracket in Eqs. (7) to (12).

The overall cost of the superstructure is the cost of the main girders, plus the cost of the cable steel.

$$
\text { Cost } 1=\frac{\gamma P L^{2}}{\sigma_{c}} C\left(B_{c}+\frac{\sigma_{c}}{A_{1} \sigma_{s}} B_{s}\right)=\frac{\gamma P L^{2}}{\sigma_{c}} C K_{1}
$$

where $K_{1}=$ cost coefficient of the super-structure ; $C=$ the price of cable steel per unit weight; and $A_{1}=$ the ratio of the prices of cable steel to normal steel.

\section{(4) Cost of Superstructure Including Selfweight}

To include the effect of the selfweight of the main girders and the cable, a new equivalent load is defined. The weight of the main girders and cable is considered as an uniformly distributed load acting on the bridge.

Equivalent load for suspension bridges:

$P_{e}=P+\left(w_{c}+w_{s}\right) / L(1+2 R)$

For fully anchored suspension bridges, $w_{s}=0$.

Equivalent load for cable-stayed bridges :

$P_{e}=P+w_{s} / 2 L+w_{c} / 4 L$

In cable-stayed bridges it is assumed that the weight of the cable is carried half by the main girders and half by the towers.

Substituting Eq. (15) into Eq. (13), and solving these simultaneous equations, the formulas for suspension bridges including the effect of the selfweight are obtained as follows $(i=s$ or $i=c)$.

$$
w_{i}=\frac{\gamma P L^{2}}{\sigma_{i}} D_{i}, \quad D_{i}=B_{i}\left[1-\frac{B_{c} \gamma L}{\sigma_{c}(1+2 R)}-\frac{B_{s} \gamma L}{\sigma_{s}(1+2 R)}\right]^{-1}
$$

Substituting Eq. (16) into Eq. (13), the formulas for cable-stayed bridges including the effect of the selfweight are obtained as follows $(i=s$ or $i=c)$.

$$
w_{i}=\frac{\gamma P L^{2}}{\sigma_{i}} D_{i}, \quad D_{i}=B_{i}\left[1-\frac{B_{c} \gamma L}{4 \sigma_{c}}-\frac{B_{s} \gamma L}{2 \sigma_{s}}\right]^{-1}
$$

Therefore the cost of superstructure including the effect of the selfweight is :

Cost $2=\frac{\gamma P L^{2}}{\sigma_{c}} C\left(D_{c}+\frac{\sigma_{c}}{A_{1} \sigma_{s}} D_{s}\right)=\frac{\gamma P L^{2}}{\sigma_{c}} C K_{2}$

(5) Cost of Towers

a) Suspension Bridges

Assuming that the cross sections of the tower vary linearly from the bottom to the top, the cross sectional area $A_{z}$ at the distance $z$ from the top of the tower is given as follows ( Fig. 2):

$$
A_{z}=A_{o} \frac{z}{H_{t}}+A_{H}\left(1-\frac{z}{H_{t}}\right)
$$

in which $A_{H}, A_{o}=$ the cross sectional area at the top and the bottom of the tower respectively, $H_{t}=$ the total 
height of the tower and $H_{4}=$ the tower height up to the main girders.

Since the top of the tower is subjected to the load $P_{e} L(0.5+R), A_{z}$ is obtained by Eq. (21).

$$
A_{z}=\left[P_{e} L(0.5+R)+\int_{c}^{z} A_{z} \gamma d z\right] / \bar{\sigma}_{s c o}
$$

in which $\sigma_{s c o}=$ allowable compressive stress for the steel used in the tower. In this paper this allowable stress is decided by the Japan Specification for Highway Bridges. Radius of gyration is assumed to have constant value of 2 , and the coefficient of effective buckling length is assumed to be 0.7 .

Substituting Eq. (20) into Eq. (21), $A_{H}$ and $A_{o}$ are expressed as follows.

$$
\begin{aligned}
& A_{H}=P_{e} L(0.5+R) / \bar{\sigma}_{s c o} \ldots \ldots \ldots \ldots \ldots . . . \\
& A_{o}=\frac{P_{e} L(0.5+R)}{\left(\bar{\sigma}_{s c o}-0.5 \gamma H_{t}\right)}\left(1+\gamma H_{t} / 2 \bar{\sigma}_{s c o}\right)
\end{aligned}
$$

Therefore the total weight of two towers is:

$$
w_{t s}=0.5 H_{t}\left(A_{o}+A_{H}\right) \gamma \times 2=\left(\gamma P L^{2} / \sigma_{c}\right) D_{t s}
$$

in which

$$
D_{t s}=\frac{2 \sigma_{c} H_{t}(0.5+R)}{\left(\bar{\sigma}_{s c o}-0.5 \gamma H_{t}\right)}\left[\frac{1}{L}+\frac{\gamma D_{s}}{\sigma_{s}(1+2 R)}+\frac{\gamma D_{c}}{\sigma_{c}(1+2 R)}\right]
$$

b) Fan Type Cable-Stayed Bridges

Assuming that the cross sections of the tower vary linearly, Eq. (20) is also valid for this case. Since the top of the tower is subjected to a total load of $P_{e} L=\left(p+w_{s} / 2 L+w_{c} / 2 L\right) L$, the total weight of two towers is given by Eq. (24).

$w_{t s}=\left(\gamma P L^{2} / \sigma_{c}\right) D_{t s}$

in which

$$
D_{t s}=\frac{2 \sigma_{c} H_{t}}{\left(\bar{\sigma}_{s c o}-0.5 \gamma H_{t}\right)}\left[\frac{1}{L}+\frac{\gamma D_{c}}{2 \sigma_{c}}+\frac{\gamma D_{s}}{2 \sigma_{s}}\right]
$$

c) Harp Type and Semi-Harp Type Cable-Stayed Bridges

In these types of bridges, a tower is assumed to consist of $N / 2$ towers whose cross sections vary lineally as shown in Fig.3. Using the $i$-th height of tower $h_{l}$, the weight of two towers is expressed as follows (see section a)).

$$
w_{t h}=\sum_{i=1}^{i=N / 2} \frac{4 \gamma h_{i} P_{e} L}{N\left(\bar{\sigma}_{s c o}-\gamma h_{i} / 2\right)}=\frac{\gamma P L^{2}}{\sigma_{c}} D_{t h}
$$

in which

$$
D_{t h}=\frac{4 \sigma_{c}}{N}\left(\frac{1}{L}+\frac{\gamma}{2 \sigma_{c}} D_{c}+\frac{\gamma}{2 \sigma_{s}} D_{s}\right) \sum_{i=1}^{i=N / 2} \frac{h_{i}}{\bar{\sigma}_{s c o}-0.5 \gamma h_{t}}
$$

d) Cost of Towers

The total cost of superstructure and towers is,

Cost $3=\frac{\gamma P L^{2}}{\sigma_{c}} C K_{3}, K_{3}=K_{2}+D_{t} / A_{2}$

in which $A_{2}=$ the ratio of the prices of cable steel to tower steel.

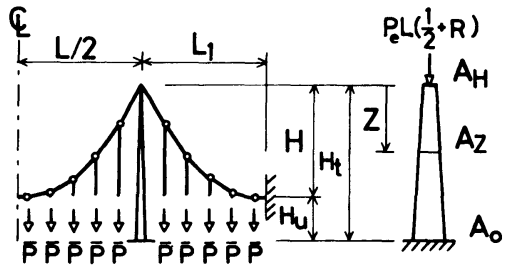

Fig. 2 Tower of Suspension Bridge.

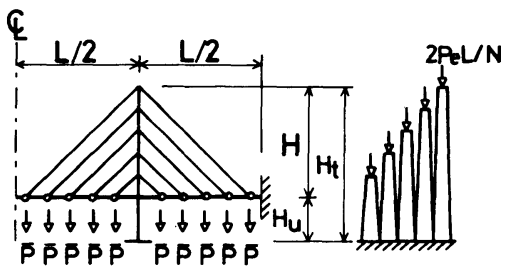

Fig. 3 Tower of Harp Type Cable-Stayed Bridge. 


\section{(6) Cost of Anchorage}

It is clear from other reports that in short and medium span suspension bridges, the ratio of steel weight of anchor frame to cable is between 0.14 and 0.46 (mean value 0.27 ). In this study, for both suspension and cable-stayed bridges, the weight of the anchor frame in the fully anchored bridge is $30 \%$ of the cable weight. On the other hand the weight of the anchlor frame in self anchored bridges may be considered to be zero. In partially anchored bridges, the weight of the anchor frame is interpolated by the location of the expansion joints. Assuming that the cost of the anchorage becomes a value $\beta$ times as much as the cost of anchor frame, the total cost of the superstructure, tower and the anchorage is expressed as follows.

Cost $4=\left(\gamma P L^{2} / \sigma_{c}\right) C K_{4}$,

$$
K_{4}=K_{3}+\bar{\alpha} \beta D_{c} / A_{1}
$$

in which the value of $\bar{\alpha}$ is :

$\bar{\alpha}=0$; self anchored bridge,

$\bar{\alpha}=0.3$; fully anchored bridge,

$\bar{\alpha}=0.3-0.6 k / N$; partially anchored cable-stayed bridge.

$\beta$ is a coefficient greater than 1 and depending on the site condition for anchorage.

\section{NUMERICAL RESULTS AND CONSIDERATIONS}

In the following numerical examples, the values shown below are used.

$\sigma_{c} / \sigma_{\text {ste }}=4, \sigma_{\text {sco }} / \sigma_{\text {ste }}=0.8, \gamma=7.85, A_{1}=A_{2}=10, R=0.4, H_{u}=0$

(1) Variation of Cost $3\left(K_{3}\right)$ with the change in the Number of Hangers.

Cost 3 are plotted for suspension bridges, harp and fan type cable-stayed bridges varying the number of hangers(stays) in Fig. 4. In this example, $k=N / 4$ is used for partially anchored bridges. It can be observed that $K_{3}$ increases only for harp type fully anchored cable-stayed bridges according to the increase in number of $N$, and $K_{3}$ almost converges at about $N=30$ for all types of bridges (the difference of $K_{3}$ for $N=$ 32 and $N=80$ is less than $1.3 \%$ for all types of bridges).

Fig. 5 shows the relationship between length of the main span and number of hangers(stays) for 41 suspension and cable-stayed bridges constructed in Japan and other foreign countries. From these data, the following regressional equations may be obtained (solid curve in Fig. 5).

$$
N=4.728 L^{0.4}-7.175 \text {. }
$$

In the following examples, the number of hangers in suspension bridges coincides with the number of stays in cable-stayed bridges, and a multiple of 4 nearest to the regressional curve should be used.

(2) Variation of Cost 3 and $4\left(K_{3}, K_{4}\right)$ with the Change in the Location of the Expansion Joints Cost 3 and 4 for harp type and fan type cable-stayed bridges varing the locations of expansion joints $(k)$

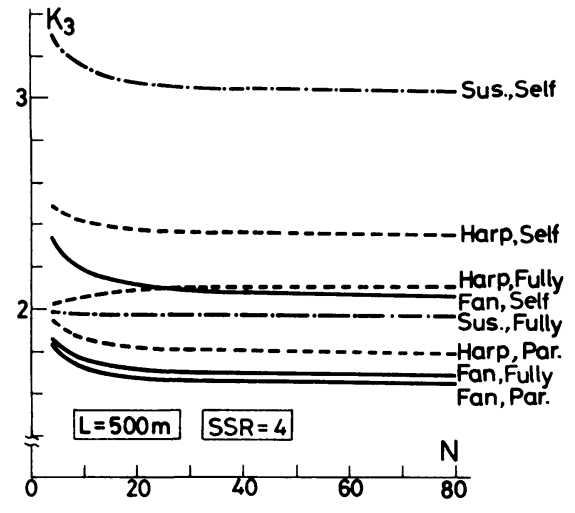

Fig. $4 K_{3}-N$ Curves.

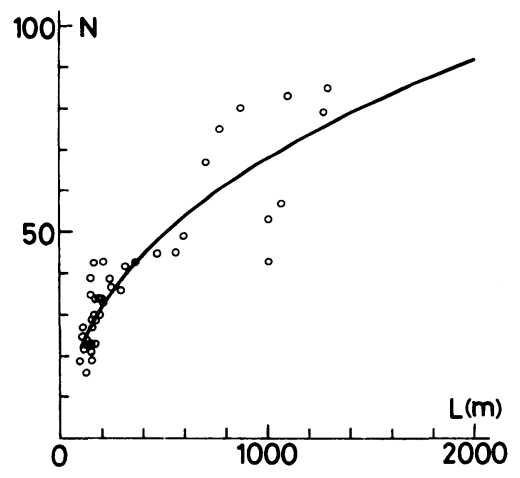

Fig. 5 Relationship between $N$ and $L$. 
are plotted in Fig. 6.

Solid lines show Cost 3. $K_{3}$ becomes minimum at $k=14$ and maximum at $k=34$ (self anchored). The variation of $K_{3}$ becomes large according to increasing in the value of SSR.

Dotted lines show Cost $4(\beta=10)$. The location of $k$ at which Cost 4 takes a minimum changes slightly compared to the case of Cost 3 , but it can be said that in partially anchored cable-stayed bridges the cost becomes minimum when $k$ nearly equal to $N / 4$. In the following example $k=N / 4$ is adopted in partially anchored bridges.

\section{(3) Comparison of Cost $3\left(K_{3}\right)$ for Various Types of Bridges}

The values of $K_{3}$ are shown in Fig. 7 for 11 types of bridges varying the length of the center span from 20 $\mathrm{m}$ to $2000 \mathrm{~m}$ and with $S S R=10$. For semi-harp type cable-stayed bridges, a value of $\alpha=0.5$ is used.

From this figure, it is clear that the most economical structure is the partially anchored fan type cable-stayed bridge up to span lengths of $1500 \mathrm{~m}$. It can be also seen that the fully anchored fan type is more economical than the suspension bridges up to the lengths of $900 \mathrm{~m}$.

(4) Variation of Cost $3\left(K_{3}\right)$ with the Change in the Span Sag Ratio

Span sag ratio between 8 and 12 are commonly used for suspension bridges. Although the mechanical efficiency of the cable increases as the $S S R$ decreases, the range of $S S R$ abovementioned is generally used due to the necessity of aerodynamical stability. On the other hand the $S S R$ for cable-stayed bridges is generally between 4 and $6 . S S R$ values used in Fig. 7 are the same for all types of bridges, and the value of $S S R$ is unconvenient for cable-stayed bridges.

In Fig. $8 K_{3}$ are plotted for 4 types of bridges with values of $S S R$ varing from 1 to 12. It can be observed that suspension bridges with values of $S S R=10$ are more expensive than the cable-stayed bridges with values of $S S R=5$. This is shown more clearly in Fig. 9, which shows that all types of cable-stayed bridges with values of $S S R=5$ are more economical than suspension bridges with values of $S S R=10$.

(5) Comparison of Cost $3\left(K_{3}\right)$ for Various Heights of Lowest Cable

Fig. 10 is obtained by varying the ratio of lowest cable height to tower height $(\alpha)$. It is clear that $K_{3}$ decreases with the increase in the ratio. Therefore from the view point of economy, the cables should be concentrated on the top of the tower.

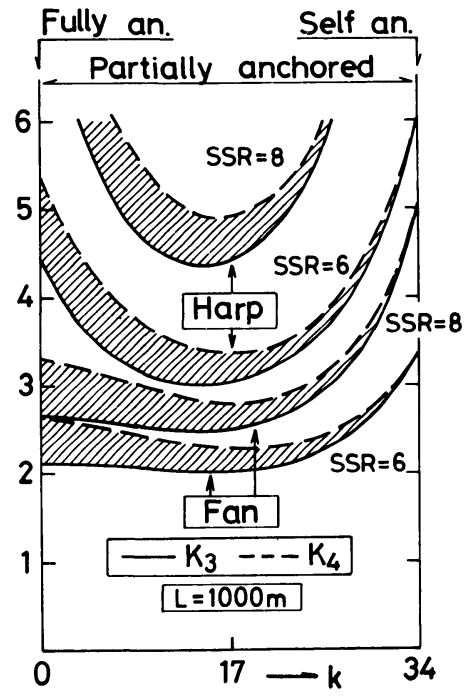

Fig. 6 Variation of $K_{3}$ and $K_{4}$ by Changing $k$.

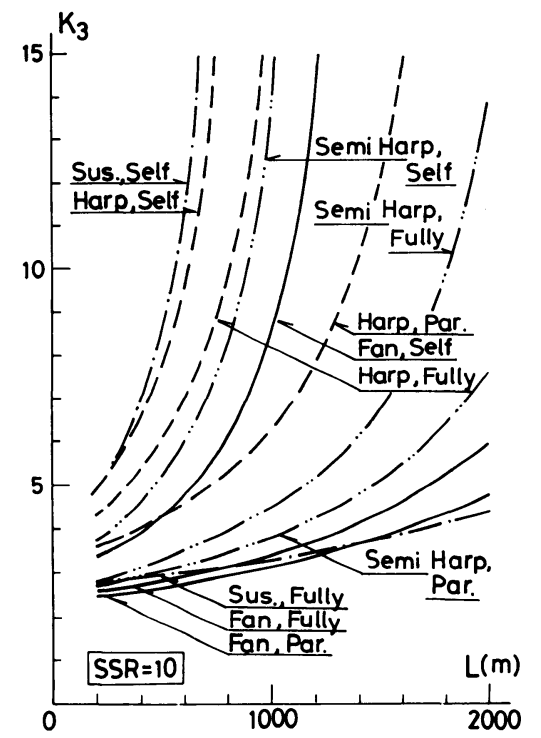

Fig. $7 K_{3}-L$ Curves for All Bridge Types with Same Span Sag Ratio. 

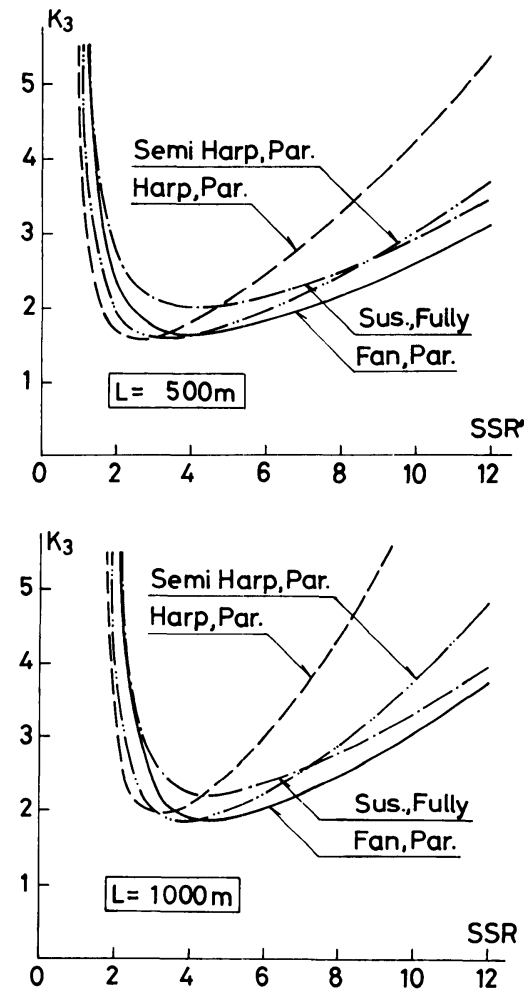

Fig. $8 K_{3}-S S R$ Curves for Partially Anchored CableStayed Bridges and Suspension Bridges.

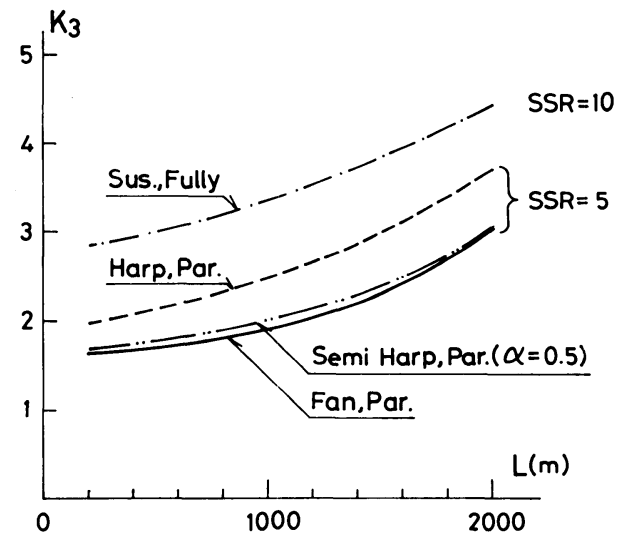

Fig. $9 K_{3}-L$ Curves for Partially Anchored Cable-Stayed Bridges and Suspension Bridges with Different $S S R$.
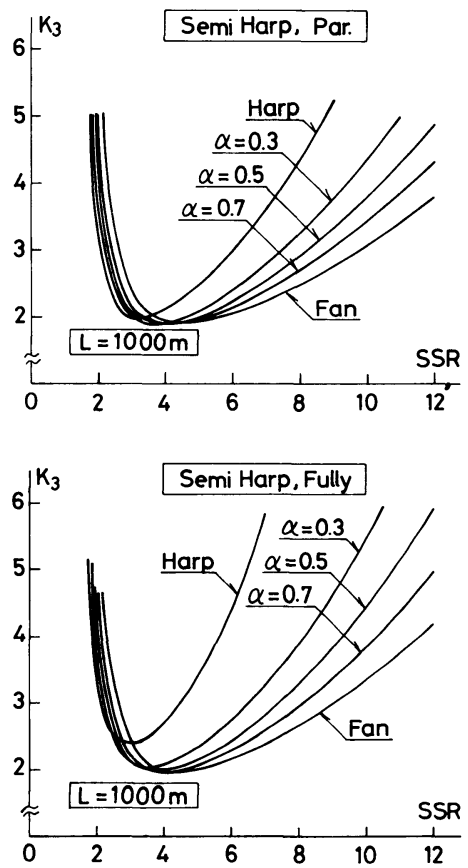

Fig. $10 K_{3}-S S R$ Curves for Cable-Stayed Bridges.

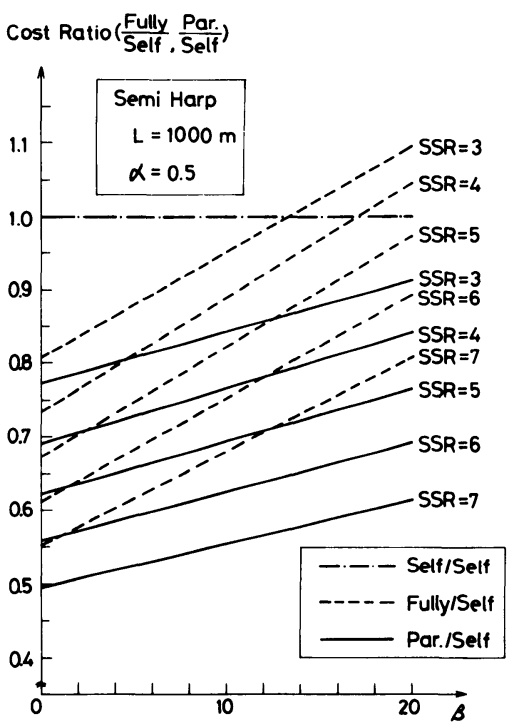

Fig. 11 Cost ratio- $\beta$ Curves for Cable-Stayed Bridges.

(6) Variation of Cost Ratio with the Change in the Cost of the Anchorage

Fig. 11 shows the cost ratio of fully and partially anchored cable-stayed bridges to self anchored cable-stayed bridges. The vertical axis is cost ratio and the horizontal axis is $\beta$ (cost ratio of anchorage to anchor frame). From this figure it can be observed that cost ratios decrease according to the increase in the value of $S S R$ and that partially anchored structures are cheaper than fully anchored structures with the same $S S R$ value. Partially anchored structures are always cheaper than self anchored ones up to a value of $\beta=20$. 


\section{CONCLUSION}

The formulas to compare the cost of cable-stasyed bridges and suspension bridges have been developed.

Fully, self and partially anchored cable-stayed bridges, and fully and self anchored suspension bridges are considered. The types of cables treated here are fan, harp and semi-harp. The structural components considered in the cost snalysis are cables, hangers, steel in main girders, towers and anchorages.

The effects of number of hangers and cables, span sag ratio, the locations of expansion joints and anchorages on the cost of cable-stayed and suspension bridges have been investigated through the numerical calculations. Numerical results show that the partially anchored fan type cable-stayed bridges are the most efficient for long span bridges. Therefore the investigation of static and dynamic behavior of partially anchored cable-stayed bridges may be an important research subject.

\section{REFERENCES}

1) Gimsing, N.J. : Anchored and Partially Anchored Stayed Bridges, Proc. of the Int. Symp. on Suspension Bridges, Lisbon, Portugal, pp.475 484, 1966.

2) Gimsing, N.J. : Cable Systems for Bridges, Proc. of 11 th Congress of the IABSE, Vienna, Austria, pp.727 732, Aug. 31 Sep. 5, 1980.

3) Gilsanz, R.E. and Biggs, J.M. : Cable-Stayed Bridges : Degrees of Anchoring, Proc. of ASCE, Journal of Structural Engineering, Vol.109, No.1, pp.200 220, January, 1983.

(Recieved March 5 1984) 